\title{
Gênese de uma obra e esboço de uma poética: a correspondência de João Guimarães Rosa
}

\author{
Origin of a work and the sketch of poetry: the correspondence of João Guimarães Rosa \\ Edna Maria Fernandes dos Santos Nascimento \\ Universidade Estadual Paulista - Araraquara - São Paulo - Brasil
}

\begin{abstract}
Resumo: A qualidade e a diversidade do material - questionários, glossários, anotações, desenhos, comentários sobre a obra, reflexões sobre língua e literatura, indicações e referências bibliográficas - que encontramos ao ler a correspondência de João Guimarães Rosa com os tradutores de seus textos para outros idiomas atestam a importância para o estudo de sua obra. Neste artigo, pretendemos comentar alguns trechos dessa correspondência, principalmente da inédita pertencente ao Fundo João Guimarães Rosa (IEB/USP), que julgamos relevantes para elucidar o processo da gênese dessa obra e para configurar uma poética rosiana ou como o autor denominava sua "plataforma" de escritor.
\end{abstract}

Palavras-chave: Guimarães Rosa; Correspondência; Gênese; Poética

\begin{abstract}
The quality and the diversity of the material - questionnaires, glossaries, notes, drawings, comments on his work, reflections on language and literature, indications and references - which we find when we read the correspondence of João Guimarães Rosa with the translators of his texts to other languages certify the importance to the study of his work. In this research, we intend to comment on some excerpts of this correspondence, mainly on the unpublished ones, which belong to the Guimarães Rosa Fund (IEB/USP), that we consider relevant to elucidate the process of the origin of this work and to shape Rosa's poetry or as the author used to call his "platform" of writer.
\end{abstract}

Keywords: Guimarães Rosa; Correspondence; Origin; Poetry

\section{Fundo João Guimarães Rosa e a correspondência do escritor}

Embora pertencente ao Instituto de Estudos Brasileiros da Universidade de São Paulo (IEB-USP) desde 1973, conforme Processo de Cessão por parte dos herdeiros, o acervo do escritor mineiro João Guimarães Rosa só começou a ser organizado a partir de 1979, após a realização de um levantamento pela Professora Doutora Cecília de Lara, pesquisadora desta Instituição, com a finalidade de identificar todo o material. Esta primeira verificação dos documentos, que passou a ser denominado Arquivo João Guimarães Rosa, hoje Fundo João Guimarães Rosa, permitiu a elaboração de um instrumento básico de trabalho - o Inventário Prévio. Em artigo publicado na revista Travessia, a conhecida pesquisadora da obra rosiana comenta a importância desse trabalho:
[...] o Inventário Prévio - norma primária para desencadear qualquer trabalho de arquivamento, pois a relação completa dos documentos permite que se desenvolvam com segurança as etapas seguintes de organização efetiva. Além disso, o registro escrito contribui para a diminuição das possibilidades de extravio, no processamento da documentação - fase que geralmente se alonga no tempo, pela própria natureza do trabalho. O Inventário Prévio permitiu, embora em caráter precário, acesso à consulta de especialistas, nessa fase. (LARA, 1987, p. 154)

A essa primeira fase do trabalho, que já permitia, embora em caráter precário, a consulta de especialistas, seguiu uma segunda que contou com a participação de Maria Célia de Moraes Leonel, na época elaborando tese de doutorado e Sandra Guardini Teixeira de Vasconcelos, preparando o mestrado, ambas interessadas em realizar trabalhos de pesquisa tendo como base a documentação do 
arquivo do escritor. Num terceiro momento, oficializada a função de Estagiário pelo Regulamento Interno do IEB, formou-se uma equipe sob a responsabilidade da professora Cecília de Lara, de que fizeram parte, entre outros, as pesquisadoras já citadas e eu, que na época também elaborava tese sobre o autor.

Formada a equipe, a partir do segundo semestre de 1982, iniciou-se a organização mais detalhada das séries ${ }^{l}$ do acervo do escritor, desenvolvendo-se uma ação em profundidade, de exame minucioso de cada documento. Com a finalidade de facilitar a consulta desses documentos e sua preservação, responsabilizei-me, juntamente com as Professoras Lenira Marques Covizzi e Iná Valéria Rodrigues Verlangieri, sob a orientação da Professora Cecília de Lara, pela organização da correspondência ativa e passiva de João Guimarães Rosa.

A série Correspondência compõe-se de cerca 950 cartas, que se referem ao período de 1934 a $1969^{2}$. As cartas escritas por Guimarães Rosa são cópias datilografadas com algumas anotações manuscritas e, às vezes, com ilustrações; as dos destinatários, na sua grande maioria, são originais datilografados. Nessa vasta e diversificada correspondência trocada com amigos, parentes, estudiosos de sua obra, editoras, chamam a atenção as longas cartas escritas aos seus tradutores Edoardo Bizzari, Harriet de Onís, Curt Meyer-Clason, J. J. Villard, Angel Crespo em que o escritor, preocupado com a versão de seus textos para outros idiomas, tece comentários sobre diferentes aspectos da construção da sua obra e, muitas vezes, elabora verdadeiros glossários para elucidar o sentido de termos científicos, regionais ou de neologismos cunhados por ele.

A organização original, em dezenove pastas suspensas, estabelecida pelo autor e por sua secretária e amiga D. Maria Augusta de Camargos Rocha, agrupava as cartas, muitas vezes, por assunto e por destinatário. Esse critério de organização, porém, nem sempre fica claro. Em uma mesma pasta encontravam-se cartas de e para diferentes destinatários, sobre assuntos diversos, e mesmo material que não é correspondência, como por exemplo:

Pasta 2: Rascunhos: Miscelânia. Cartas recebidas/ enviadas por Guimarães Rosa; memoranduns e relatórios referentes ao Ministério das Relações Exteriores: apresentação de Tutaméia para Pulso; Introdução ao livro "De Sete lagoas aos Sete Mares"; envelope contendo convites para despedidas, memorandum, carta sobre a palavra tutaméia.

\footnotetext{
O espólio de João Guimarães Rosa, organizado, sob a supervisão da Prof $^{a}$ Dra. Cecília de Lara, na época encontra-se distribuído nas seguintes séries: Originais, Estudos para a obra, Correspondência, Coleção Guimarães Rosa (Biblioteca do escritor).

2 A data da morte de Guimarães Rosa é 19/11/1967, mas as mensagens de pêsames após essa data já faziam parte da correspondência na ocasião da aquisição do material pelo Instituto de Estudos Brasileiros. Na nossa organização, elas continuaram a integrar a Série Correspondência sob a denominação Correspondência Complementar.
}

Parte dessa correspondência já foi publicada, em duas edições: J. Guimarães Rosa: correspondência com o tradutor italiano. São Paulo: Instituto Cultural Ítalo-Brasileiro. Caderno no 8, 1972 (edição única de 1000 exemplares numerados); J. Guimarães Rosa: correspondência com o tradutor italiano Edoardo Bizzari. São Paulo: T.A. Queiroz/ Instituto Cultural ÍtaloBrasileiro, 1982; e em uma única edição: João Guimarães Rosa: correspondência com seu tradutor alemão Curt Meyer-Clason. (1958-1967). Belo Horizonte: UMFG, 2003; Cartas a William Agel de Mello: correspondência Guimarães Rosa. São Paulo: Ateliê, 2003. A pesquisa de Iná Valéria Rodrigues Verlangieri com a correspondência ativa e passiva de João Guimarães Rosa resultou na dissertação de mestrado intitulada J. Guimarães Rosa: correspondência inédita com a tradutora norte-americana Harriet de Onís. Também foram publicadas cartas não pertencentes ao Fundo João Guimarães Rosa nos seguintes livros: DANTAS, Paulo. Sagarana emotiva. São Paulo: Duas Cidades, 1975; GUIMARÃES, Vicente de Paula. Joãozito: infância de João Guimarães Rosa. Rio de Janeiro: José Oympio/INL, 1972; ROSA, Vilma Guimarães. Relembramentos: João Guimarães Rosa, meu pai. Rio de Janeiro: Nova Fronteira, 1983.

No artigo "Interesse geral de uma correspondência particular", publicada a 20 de maio de 1975 no suplemento literário d' O Estado de S. Paulo, Paulo Rónai salienta a importância da divulgação da correspondência que boa parte ainda permanece inédita, principalmente aquela relativa aos tradutores, onde o autor responde a "procustos":

Em vários trechos da correspondência, alude ele a outros "procustos", questionários semelhantes aos de Bizzari, e ainda mais copiosos, que lhe submeteram outros tradutores, especialmente a Sra. de Onís, a quem são devidas as versões inglesas de Sagarana e de Grande sertão: veredas; as suas respostas a esta senhora e a Meyer-Clason (já publicadas parcialmente na Alemanha), assim como a Jean Jacques Villard e a Angel Crespo, que perfazem alguns volumes, constituem um comentário quase completo de seus maiores livros e possuem, por isso, um interesse prodigioso. (RÓNAI, 1975, p. 6)

O contato direto com esses documentos e sua organização foram delineando o valioso material que eu tinha nas mãos e que foi utilizado na minha tese de doutorado intitulada "Estudo da metalinguagem natural na obra de Guimarães Rosa" e em outros textos. Neste artigo, pretendo comentar alguns trechos da correspondência de Guimarães Rosa que julgo importantes para elucidar o processo da gênese da sua obra e para configurar uma poética rosiana ou como o autor denominava sua "plataforma" de escritor. 


\section{A elaboração da obra}

A linguagem de Guimarães é única. Essa afirmação há muito é um consenso entre aqueles que simplesmente leem seus textos ou para aqueles que fazem de sua obra objeto de estudo. Inúmeros críticos já chamaram a atenção para os jogos sonoros, para as metáforas e para os neologismos do texto rosiano cuja textura verbal cobre a dupla extensão das categorias prosa e poesia. Oswaldino Marques em seu ensaio pioneiro "Canto e plumagem das palavras" (1957, p. 21), à falta de um termo corrente, cunha o neologismo prosoema para nomear a expressão literária de Guimarães Rosa. Essa consonância perfeita entre o plano do conteúdo e o plano da expressão, que identifica o estilo rosiano, é fruto de muito trabalho.

O trabalho de elaboração da forma está presente ao longo de toda obra rosiana imprimindo-lhe características próprias. Para chegar à forma de expressão precisa, Guimarães Rosa trabalhava muito. O trecho "Genialidade, pois sim. Mas eu digo: trabalho, trabalho, trabalho!", que se encontra na entrevista a Günter W. Lorenz (ROSA, 1971, p. 292), exprime a atitude do escritor em relação ao fazer literário. De fato, a sua obra demonstra que o texto literário é fruto de um contínuo e árduo trabalho. Parte de seu trabalho de coleta de material, de busca da forma precisa e de criação léxica pode ser reconstituída na leitura de sua correspondência. Além disso, nela é possível desvendar seu diálogo com outros textos.

A coleta do material processa-se de diferentes formas. O trecho de "Conversa de bois", conto de Sagarana, que descreve o acidente com Agenor Soronho e a formidável reação dos bois em favor do menino Tiãozinho, é registrado com acuidade pelo escritor, como ele próprio comenta em correspondência à Harriet de Onís:

Trata-se de narração real, e raríssima, de um caso que aconteceu, de fato, realmente. As palavras e expressões, do carreiro, que me contou sua dramática experiência, foram por mim quase que "taquigrafadas", ispsi verbis. É um relato vivo, importante. (ROSA, 05/02/1965) 3

O contato direto com os animais no zoológico era também uma fonte para sua escritura como confessa o escritor a Mário Calábria:

Peguei-me com o coração me lembrando aquela nossa entretida ida ao Parc Zoologique de Vincennes, onde os bisões gorjeiam e as girafas (maluco-metódicas) galopam ... [...] E mesmo para mim, depois dessa experiência, desta mágica aventura, passei a saber coisas novas a respeito do ouriço e da folha de faia. [...] É perto dos bichos que os homens se amam mais. (ROSA, 12/06/63)

\footnotetext{
3 Quando no corpo do artigo não constar o nome do destinatário da correspondência, ele será indicado juntamente com a data que consta na carta, logo após a citação.
}

A busca da forma precisa revela-se nas frequentes consultas a dicionários que levam o autor a descobrir enganos e a fazer correções e sugestões ao dicionarista, como ele comenta em carta a Harriet de Onís:

Aqui, como em outros pontos, o termo "rancho" foi traduzido por "shack", palavra que vem traduzindo também "cafua". Como essas designações aparecem com grande frequência em meus livros, gostaria que as precisássemos. "Cafua", cabana, choupana, penso que se traduzem bem por "shack", por "hut". "Rancho", porém, (que, aliás, não está bem definido no "Pequeno Dicionário da Língua Portuguesa" - e vou falar com o Autor que o corrija na edição próxima), é uma construção rústica diferente: é um abrigo simplíssimo, no campo, sem paredes (ou às vezes só com uma parede), apenas com 4 esteios e um teto de capim seco ou de palha de coqueiro, só excepcionalmente de telas [sic] (quando, então, se chama telheiro). É um barracão, galpão ou coberta, em geral, extremamente primitivo. O mais das vezes, não tem proprietário habitador; serve apenas para vaqueiros ou viajantes se abrigarem à noite ou durante a chuva. Ou, quando, tem dono fixo, é apenas morada provisória de caçadores, pescadores, ou trabalhadores. (ROSA, 09/05/59)

O auxílio de livros especializados ou mesmo de pessoas especializadas para a denominação e descrição precisa de animais, principalmente bois e cavalos, é uma constante:

Acabo de descobrir um livro: "THE BIRDS OF BRITISH GUIANA", por Frederick Vavasour Maccornell/Charles Chubb, Londres, 1916. Assim também, acho que deve haver aí alguns livros que deem relacionadas as cores e sinais dos bois e dos cavalos, com respectivos termos usados no West. Os professores de Zoologia, da universidade, poderiam informar, a este respeito. Seria importantíssimo para a revisão de "O BURRINHO PEDRÊS" e para a versão dos "CORPO DE BAILE" e "CONVERSA DE BOIS". (ROSA, 04/11/64, carta à Harriet de Onís)

As anotações sobre animais, geografia, flora, termos regionais constituem-se em verdadeiros glossários. Em geral, os vocábulos em ordem alfabética, são acompanhados do nome científico ou regional, de definição, de sinonímia ou de versão para outra língua, quando eles fazem parte de correspondência com um tradutor. Em carta à Harriet de Onis (ROSA, 15/12/1963), encontramos uma lista de palavras arroladas sob a denominação “ÁRVORES E PLANTAS (Notas sobre algumas plantas)" que exemplificam o acurado e minucioso trabalho do escritor em mostrar para a tradutora o sentido preciso de cada termo em português e em sugerir para ela termos correspondentes na língua inglesa. 
Em "NOVAS Notas para o "Conversa de bois", também em carta dirigida à Harriet de Onis (ROSA, 05/01/1965), além de anotações sobre termos do conto, há desenhos feitos à mão pelo escritor de partes do carro de boi, da localização das parelhas de bois - Buscapé, Namorado; Capitão, Brabagato; Dansador, Brilhante; Realejo, Canindé - e das personagens Agenor Soronho e Tiãozinho.

A busca da forma precisa para a versão da sua obra para outros idiomas é uma constante e o autor acompanha passo a passo o processo de tradução, explicando etimologias, esclarecendo usos e costumes brasileiros, comparando as diferentes denominações de um mesmo termo em outras línguas:

TATARANA $[\ldots]=$ lagarta-de-fogo. (fire caterpillar) Do tupi (língua dos índios): tatá $=$ fogo; ... rana $=$ sufixo equivalente ao ... like inglês. Que-parece-fogo. Porque é uma lagarta (larva de borboleta) ruiva, com pelos que queimam a pele da gente, ao mínimo contato causando dores terríveis. (ROSA, 21/05/1959, carta à Harriet de Onís)

Barra azul: a parte inferior das paredes das casas, que, no interior do Brasil. São em geral pintadas a cores. No caso: azul = blue. $($ ROSA, 04/03/1965, carta à Harriet de Onís)

DESPACHO: "embrulho com feitiçaria deixado em certos lugares para influir na vontade alheia ou como oferenda a alguma divindade de macumba" [...] Contém em geral uma galinha assada, charutos, etc. Aqui no Rio, à noite, principalmente nas primeiras sextas-feiras de cada mês, vêem-se muitos "despachos". Não são embrulhos. (ROSA, 23/11/1964, carta à Harriet de Onís)

Para a guaxima, encontro num Dicionário de Botânica que é vegetal chamado, aí em Puerto rico, buenas tardes; que no México se chama botón de oro. [...] No mesmo Dicionário, acho para grão de gado que é chamado de cockspur nos Estado Unidos, e de azufaifo aí em Puerto Rico. (ROSA, 03/04/1964, carta à Harriet de Onís)

Quanto às formas novas cunhadas por ele, na correspondência, o escritor explica seus neologismos, usando, inclusive uma terminologia científica. No exemplo a seguir, há uma "polissemia complexa", segundo denominação de Guimarães Rosa, que explica a MeyerClason a composição do neologismo como resultado possível de duas formações: o cruzamento de terrível + pavoroso ou como composição do vocábulo terra + o radical voro, servindo de segundo elemento. O texto do conto "Benfazeja", onde se encontra o neologismo, segue a citação da carta:

\begin{abstract}
TERRIVOROSOS $=$
De terrív(el) + (pa)voroso

Mas também de:

Terr(a) $+[\ldots]$ voro (de devorar)

(Cf. a expressão usual: "com estes olhos que a terra há de comer...”)

É uma polissemia complexa, cheia de fortes sugestões. Sugiro aproveitar para exemplificação, no seu estudo que acompanhará o livro. (ROSA, 17/08/1966)

E, nunca se esqueçam: tomem na lembrança, narrem aos seus filhos, havidos ou vindouros, o que vocês viram com esses seus olhos terrivorosos, e não souberam impedir, nem compreender, nem agraciar. (ROSA, 1972, p. 134)
\end{abstract}

Como fonte para a compreensão de suas criações, a correspondência torna possível não só elucidar o processo que deu origem ao neologismo, mas também seu significado. Motivado pela dificuldade de tradução desses neologismos, esclarece:

No original: "canhim": Outro exemplo de polissemia. Canhim, e "cainhar" = "latir dolorosamente o Cão" e de "cainho" = "próprio de Cão". Mas também, CAIM, irmão de Abel.” (ROSA, 17/08/66, carta a Curt Meyer-Clason)

O nome do personagem Matraga é homônimo da expressão " $m$ 'a traga". Sua escolha trocadilhesca e sua simbologia no conto "A hora e vez de Augusto Matraga" são explicitadas em carta à Harriet de Onís:

O nome MATRAGA. Quando eu estava escrevendo o conto, quis um nome, estranho, para ser assumido pelo herói somente no final, quando, redimido e transformado, "recebe um nome novo" (creio que isto é do "Apocalypse"). Qualquer nome serviria, mesmo sem ter, em si alguma significação especial. Nessa ocasião, ouvi alguém, que gostava de falar com excessivo apuro, dizer, ao telefone: ... que ele ma traga). Achei importante, pelo simbolismo, pois, no fim, o herói ainda pensa na mulher, na Dona Dionora. Naturalmente, o "sentido" desse simbolismo só se explicaria no plano metafísico. De qualquer modo, o nome vale pela sua força e beleza próprias: 3 vezes a vogal a, e consoantes enérgicas. (ROSA, 04/03/ 1965)

É na correspondência com Edoardo Bizzari que ele decifra o anagrama "Aí, Zé, ôpa!", usado em "Cara de Bronze" (1969, p. 126):

Na página 620, há um oculto desabafo lúdico, pessoal e particular brincadeira do autor, só mesmo para seu uso, mas que mostrar a Você, não resisto: "Aí, Zé, ôpa", intraduzível evidentemente: lido de trás para

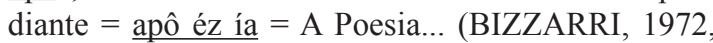
p. 120. Grifos do autor) 
Para fugir do lugar comum, além de criar formas novas, Guimarães Rosa desconstrói formas estereotipadas. Testemunham a elaboração dessas desconstruções algumas passagens da correspondência. Nesses trechos, o autor determina seu significado, explica sua origem, e mais, esclarece a função na obra: esse procedimento é utilizado para conseguir maior efeito expressivo e mesmo obter um tom de humor. Seguem-se alguns trechos da obra ficcional, onde parece a forma desconstruída e, logo a seguir, o trecho da carta em que ele se refere à matriz:

- Ora, ora!... Esses é que são os mais!... Boi fala o tempo todo. Eu até posso contar um caso acontecido que se deu.

- Só se eu tiver de recontar diferente, enfeitado e acrescentando ponto e pouco... (Sagarana, 1965, p. 283)

[...] PONTO E POUCO... Há um provérbio que diz:"Quem conta um conto, acrescenta um ponto..." Isto é: aumenta, exagera e difama a história. Daí a título de humour jovial, a expressão que usei. O próprio Narrador vai dizendo que exagerará, de muito, a história que o Timborna lhe contar. Que acrescentará "um ponto", e ainda mais, um "pouco". (ROSA, 05/02/1965, carta à Harriet de Onís)

Porque, lá na capital, sabem montar à cossaca, em dois ginetes, e as duas facções são atendidas rotativa e relativamente. Enquanto isso, o tempo passa, o pau vai e vem, e folgam os filhos da sabedoria. (Sagarana, 1965, p. 185)

[...] O PAU VAI E VEM, E FOLGAM OS FILHOS DA SABEDORIA. Há um provérbio brasileiro que diz: "Enquanto o pau vai e vem, folgam as costas..." Supondo-se que alguém está dando pancadas nas costas do outro, com um pau, um cacete; enquanto o pau se movimenta para bater, as costas descansam. Se alegram, nos intervalos dos golpes. Nos intervalos dos sofrimentos ou importunações, a gente aproveita para ser feliz. Modifiquei o provérbio com sentido óbvio. (ROSA, 08/10/1964, carta à Harriet de Onís)

As desconstruções ocorrem também no nível da palavra como comenta o autor a respeito do termo banglafumém, utilizado em Grande sertão: veredas:

[...] é o mesmo banga-la-fumega, que está nos dicionários: quer dizer $=$ joão-ninguém, indivíduo sem valor nem importância, sujeito à-toa, legalhé, mequetrefe, borra-botas. (É termo regional, do interior bruto). (ROSA, 08/03/1966, carta a Angel Crespo)

É o próprio autor que reconhece a intertextualidade de sua obra e comenta o dialógo de seu texto com o de outros autores. Em carta a Edoardo Bizzarri, Guimarães Rosa afirma estar espantado de ver como nas novelas de
"Corpo de baile" há textos que se identificam com os de outros autores:

E eu mesmo fiquei espantado de ver, a posteriori, como as novelas, umas mais, outras menos, desenvolvem temas que poderiam filiar-se, de algum modo, aos "diálogos", remotamente, ou às "Enéadas", ou ter nos velhos hindus qualquer raizinha de partida. Daí, as epígrafes de Plotino e Ruysbroeck. [...] Quero ficar com o Tao, com os Vedas e Upanixades, com os Evangelistas e São Paulo, com Platão, com Plotino, com Bergson, com Berdiaeff - com Cristo, principalmente. (BIZZARRI, 1972, p. 67)

Outro exemplo é do conto "Minha Gente", de Sagarana. A citação aparece entre aspas em um diálogo:

Também já voltava Santana, montado num burro casmurro. E eu quis comandar, por minha vez:

- "Vamos! Partamos! Já Circe, a venerável, me advertiu..."

Mas Santana, que é criatura do Caraça, retrucou:

- "Vinde, amigos, perguntai ao estrangeiro se sabe ou se aprendeu, algum dia, qualquer jogo..." (ROSA, 1965, p. 170)

Foi na leitura da correspondência do autor com Harriet de Onís que encontramos o seguinte trecho que comprova a intertextualidade:

"JÁ CIRCE, A VENERÁVEL, ME ADVERTIU": trata-se de um verso da Odisséia, de Homero (Homer's ODYSSEY, BOOK X (Canto X), linha 54. (...) "VINDE, AMIGOS... QUALQUER JOGO". Outra citação da "Odisséia": Homer's "ODYSSEY", book VIII (Canto 8), linhas 133/134. (ROSA, 28/10/64)

\section{A plataforma do escritor}

Não é raro encontrarmos escritores que também são teóricos ou pelo menos emitem juízos teóricos sobre o processo de escritura. É o caso, por exemplo, de Vladimir Maiakóvski, Paul Valéry, Umberto Eco, José de Alencar, Mário de Andrade. O estudo dessas posições teóricas constitui-se em uma contribuição valiosa para a elaboração de uma poética de cada autor, entendida como a fundamentação do trabalho poético. Guimarães Rosa encontra-se dentre esses escritores que poderíamos dizer teorizam sua prática.

A teorização de sua escritura encontra-se, entre outros documentos que fazem parte do Fundo Guimarães Rosa, em uma carta, datada de nove de fevereiro de 1965, à Harriet de Onís. O autor preocupado com dificuldades apresentadas na tradução para o idioma inglês do trecho de "São Marcos" (Sagarana) que na edição de 1965 vai da página 235 , linha 4 , até à página 236 , linha 24 , comenta-o. 
Sua preocupação é explicada. Segundo ele, esse trecho assume importância autônoma no texto, porque é sua platform de escritor:

[...] por expor minha maneira de ver, de sentir e de pensar, a respeito das "palavras" - da PALAVRA. Trata-se de resumida declaração, intercalada na novela, de minha "platform" de escritor (pelo menos de uma parte), de uma concepção de arte: de escrita e POESIA. Em verdade, equivale a um pequeno ensaio encaixado na estória [...] (ROSA, 09/02/1965)

Nesse pequeno ensaio, encaixado na história, continua: "[...] o autor quer explicar, é sua crença no poder misterioso das palavras - no poder da palavra independente de seu simples e mero significado." (ROSA, 09/02/1965)

Intercalamos a seguir partes desse trecho de "São Marcos" a que se refere Guimarães Rosa com suas reflexões na carta sobre o significante do signo e sobre o efeito inusitado provocado pela palavra nova:

\section{Sargon}

Assarhaddon

Teglattphalasar, Salmanassar

Nabonid, Napopalassar, Nabucodonosor

Belsazar

Sanekherib

E era para mim um poema esse rol de reis leoninos, agora despojados da vontade sanhuda e só representados na poesia. Não pelos cilindros de ouro e pedras, postos sobre as reais comas eriçadas, nem pelas alargadas barba, entremeadas de fios ouro. (ROSA, 1965, p. 235)

O Narrador explica porque escreveu, no bambu, os nomes dos reis assírio-babilônios: foi como se praticasse um puro ato poético. Empolgado pela forma - rebarbativa, estranha forte, incomum, bizarra - desses nomes, em si, com o poder de estimularem, gratuitamente, a sua imaginação estética, de fazerem vibrar sua sensibilidade poética. Os nomes, o aspecto físico dos nomes, por si, valendo pela forma. (ROSA, 09/02/1965)

Só, só por causa dos nomes. Sim, que à parte o sentido prisco, valia o ileso gume do vocábulo pouco visto e menos ainda ouvido, raramente usado, melhor fora se jamais usado. (ROSA, 1965, p. 235)

(O narrador diz:) De fato. Além de carga de antiguidade, das evocações arcaicas e históricas dadas por esses nomes (pois elas também são "poetizantes"), esses nomes valiam pela sua estranhez e raridade: compara a palavra ao instrumento cortante, que tanto mais eficazmente atinge a nossa sensibilidade poética, quanto menos gasto ou estragado pelo uso comum o seu gume, o seu "corte"; isto é, melhor ainda, se fosse um nome novo, inédito, uma palavra vista ou ouvida pela primeira vez. (Por exemplo, imaginemos um rei daqueles mas que nunca existiu, e cujo nome inventamos neste instante) SAPAKRAKAL... Daí, veja, por exemplo, a Snra: a eficácia do título SAGARANA, totalmente novo, para qualquer leitor, e ainda não explicado, virgem de visão e de entendimento. Não é? Por isto, é que eu quereria que esse título fosse conservado, na tradução em inglês, e em todas as outras. (ROSA, 09/02/1965)

E não é sem assim que as palavras têm canto e plumagem. (ROSA, 1965, p. 235)

Diz-se que "não sem motivo (não inutilmente) que as palavra têm CANTO E PLUMAGEM" (As palavras são comparadas aos pássaros.) Isto é: além de seu significado, transcendendo da sua simples função instrumental de comunicação, as palavras valem, também, por seu ASPECTO VISUAL OBJETIVO e por sua MAGIA DE SONORIDADE. (São elementos que agem no nosso subconsciente. Mas o poeta tem alguma noção dessa operação inconsciente. Quando o poeta escolhe ou rejeita expressões e palavras, visa não apenas a comunicar imagens ou ideias - mas também atuar, de certa maneira, sobre a mente subconsciente do leitor) (ROSA, 09/02/1965)

E que o capiauzinho analfabeto Matutino Solferino Roberto da Silva, existe, e, quando chega na bitácula, impõe: - "Me dá dez’tões de biscoito de talxóts!" porque deseja mercadoria fina e pensa que "caixote" pelo jeitão plebeu deve ser termo deturpado. (ROSA, 1965, p. 236)

Apresenta-se um duplo exemplo de prestígio da palavra: I) - No meio de gente camponesa e pobre, humilde, batizam-se as crianças com nomes tão preciosos e rebuscados (ao ponto de ridículos), como esse MATUTINO SOLFERINO ROBERTO DA SILVA. [...] II) Quando o jovem caipira abovementioned vai comprar biscoitos, altera a palavra "caixote", por the parecer que seu verdadeiro aspecto deveria ser provavelmente mais nobre, mais fino. (O que os gramáticos chamam de "ultracorreção".) (ROSA, 09/02/1965)

E que a população de Calango-Frito não se edifica com os sermões do novel pároco Padre Geraldo ("Ara, todo mundo entende...") e clama saudades das lengas arengas do defunto Padre Jerônimo, "que tinham muito mais latim"... (ROSA, 1965, p. 236)

(Obviamente explicado.) A unção e o fervor religiosos não são despertados por explanações claras, lógicas, da inteligência reflexiva - mas provocados pelo mistério, pelo não-entendido, pelo absurdo ("Credo, quia absurdum"): cujo "roçar" pelo nosso espírito permite-nos "desconfiar" de novas e outras e desconhecidas "dimensões", e que, portanto, são capazes de revelaremnos que o universo é "mágico". (ROSA, 09/02/1965) 
[...] e que a frase "Sub lege libertas!", proferida em comício de cidade grande, pôde abafar um motim potente, iminente.) (ROSA, 1965, p. 236)

Outro exemplo do poder da palavra. Alusão a um fato que se deu em Belo Horizonte (capital do Estado de Minas Gerais). Uma multidão se dirigiu, furiosa, ao Palácio do Presidente (naquele tempo havia Presidente e não, como hoje Governador, de Estados), para reclamarem algo. O Presidente, parecendo à janela, soube conter e dissolver a fúria da multidão, proferindo apenas, inicialmente, a frase "Sub lege libertas!" - que é, aliás, o lema do Estado de Minas Gerais. (ROSA, 09/02/1965)

E que o menino Francisquinho levou susto e chorou, um dia, com medo da toada "patranha" - que ele repetira, alto, quinze ou doze vezes, por brincadeira boba, e, pois, se desusara por esse uso e voltara a ser selvagem. (ROSA, 1965, p. 236)

Quando a gente repete, muitas vezes, uma palavra, ela se desprende de seu significado - isto é, perde a sua "domesticidade", volta a ser "selvagem" - passando a ser, para nós, para quem a diz tão repetida, um estranho "objeto" sonoro. Foi o que aconteceu ao menino Francisquinho, que, com isso, se assustou e chorou. (ROSA, 09/02/1965)

A carta à Harriet de Onís é uma constante reflexão sobre o plano da expressão. Mas é nos dois últimos parágrafos que Guimarães Rosa comenta o valor que atribui à poética da forma:

[...] nos meus livros (onde nada é gratuito, disponível, nem inútil), tem importância, pelo menos igual ao do sentido da estória, se é que não muito mais: a poética ou poeticidade da forma, tanto a "sensação" mágica, visual, das palavras, quanto a "eficácia sonora" delas; e mais as alterações viventes do ritmo, a música subjacente, as fórmulas-esqueletos das frases - transmitindo ao subconsciente vibrações emotivas subtis. (ROSA, 09/02/1965)

E também explicita a função dessas manobras estilísticas. A função desses arranjos, que realçam o aspecto físico e sonoro do signo independente de seu significado, evitam o lugar-comum e atuam sobre a mente inconsciente do leitor, evitando o leitor preguiçoso, que é obrigado a buscar novos significados para a mensagem. A música subjacente às palavras transmite ao "inconsciente vibrações emotivas sutis" e constitui-se em uma manobra estilística capaz de construir um texto "vivo, ativo", no dizer de Guimarães Rosa:

E é por isto - para termos um livro vivo, ativo, um livro novo, mesmo - que temos de fugir do habitual, eliminar o raso costumeiro, condenar o lugar-comum; em suma: evitar tudo o que o leitor preguiçoso espera do autor preguiçoso. Mas, nós, não somos assim. (ROSA, 09/02/1965)

Outros trechos da sua correspondência referendam sua plataform de escritor. Discutindo com seus tradutores a melhor forma de tradução, sempre valoriza o aspecto visual da palavra e chama a atenção para a magia da sua sonoridade:

Observo, também, que quase sempre as dúvidas decorrem do "vício sintático", da servidão à sintaxe vulgar e rígida, doença de que sofremos. Duas coisas convém ter sempre presente: tudo vai para a poesia, o lugar-comum deve ter proibida a entrada, estamos descobrindo novos territórios do sentir, do pensar, e da expressividade; as palavras valem "sozinhas", cada uma por si, com sua carga própria, independentes, e às combinações delas permitem-se todas variantes e variedades. (ROSA, 24/03/1966, carta a Curt MeyerClason)

A meu ver, o texto literário precisa ter gosto, sabor próprio - como na boa poesia. O leitor deve receber sempre uma pequena sensação de surpresa - isto é, de vida. Assim, penso que nunca se deverá procurar, para a tradução, expressões já cunhadas, batidas e cediças, do inglês. Acho, também, que as palavras devem fornecer mais do que o que significam. As palavras devem funcionar também por sua forma gráfica, sugestiva, e sua sonoridade, contribuindo para criar uma espécie de "música subjacente". Daí, o recurso às rimas, às assonâncias, e, principalmente, às aliterações. Formas curtas, rápidas, enérgicas. Força, principalmente. (ROSA, 11/02/1964, carta à Harriet de Onís)

As reflexões de Guimarães Rosa sobre a prática poética, que encontramos em trechos dessa carta, podem ser agrupadas nos seguintes itens que sintetizam sua plataforma de escritor:

1. a valorização das propriedades físicas e fonéticas da palavra torna a mensagem multissignificativa a partir de seu plano de expressão;

2. a multissignificação do significante da palavra é possibilidade que se atualiza em decorrência do arranjo sintagmático. O sentido poético da linguagem não está programado no signo referencial.

3. A volta da mensagem para si mesma provoca uma ruptura da expectativa do lugar-comum automatizado na língua, atraindo atenção especial para o plano visual e sonoro do signo;

4. O significante passa a ter sentido independente do seu significado.

A palavra vale não apenas pela sua função prática, ou como denomina Guimarães Rosa, na carta enviada à 
Harriet de Onís, "função instrumental", mas pode valer também pelo que é: por seu "aspecto visual objetivo e por sua magia de sonoridade", ou por sua função poética, no dizer de Jakobson (1969): aquela em que a mensagem se volta para si mesma, focalizando a própria mensagem.

Em outros momentos da correspondência é possível recuperar o que pensa Guimarães Rosa sobre seus neologismos, essas criações que podem causar estranhamento ao leitor, se ele partir do pressuposto de que, muitas vezes, já há vocábulos de uso corrente que poderiam expressar o discurso rosiano. Mas mergulhando na correspondência, o leitor atento poderá descobrir que a cunhagem de um novo termo não substitui o termo já existente. Sua função primordial é tentar descondicionar os hábitos verbais do leitor com a finalidade de levá-lo a penetrar em um novo microuniverso. São novas formas de ver, sentir, interpretar o mundo. Guimarães Rosa, em várias passagens da sua correspondência com tradutores, explica:

Deve ter notado que, em meus livros, eu faço, ou procuro fazer isso, permanentemente, constantemente, com o português: chocar, "estranhar" o leitor, não deixar que ele repouse na bengala dos lugares-comuns, das expressões domesticadas e acostumadas: obrigálo a sentir a frase meio exótica, uma "novidade" nas palavras, na sintaxe. Pode parecer crazy de minha parte, mas quero que o leitor tenha de enfrentar um pouco o texto, como a um animal bravo e vivo. O que eu gostaria era de falar tanto ao inconsciente quanto à mente consciente do leitor. (ROSA, 02/05/1959, carta à Harriet de Onís)

Para Guimarães Rosa a busca e a criação da forma precisa revitalizam a linguagem que desgastada pelo uso perde seu poder expressivo e se torna clichê. A constante fuga do lugar-comum tem a finalidade de tirar o leitor da inércia, despertando-lhe para a poesia do texto, escreve o autor em trechos de cartas à Harrier de Onís:

Tudo é atrevimento, estranhez, liberdade, colorido revolucionário. Todo automatismo da inércia, da escrita convencional, é rigorosamente evitado. Tudo pela poesia e por caminhos novos! Acabarão aceitando. (ROSA, 03/04/1964)

E é por isto - para termos um livro vivo, ativo, um livro novo mesmo - que temos de fugir do habitual, eliminar o raso costumeiro, condenar o lugar-comum; em suma: evitar tudo o que o leitor preguiçoso espera ao autor preguiçoso. Mas, nós não somos assim. (ROSA, 09/02/1965)

Para ele, o corte de palavras ou mesmo de expressões dispensáveis para condensar mais a linguagem, a fim de evitar o óbvio, o pesado, o frouxo e o lugar comum, evidenciam a musicalidade do texto, e aconselhado a Harriet de Onís para sua versão para o inglês deve funcionar "as poked fire", como fogo atiçado:

\begin{abstract}
Naturalmente, as coisas que anotei, no sentido de um necessário aperfeiçoamento, acho que também têm de levar-se em conta. Principalmente, quanto a condensarmos mais, cortando fora palavras e expressões dispensáveis, que só servem para tornar o texto óbvio, pesado e frouxo. São como gordura excessiva, num corpo de mulher elegante ou de um atleta. E, cortando-as, teremos o que diz Rudyard Kipling na sua autobriografia: e cortes atuam "as poked fire". E atender ao ritmo, à musica. Modéstia à parte, mas já viu que o "Sagarana" é, sem nenhum lugarcomum, um poema musical. (ROSA, 24/03/1965)
\end{abstract}

Assim como adotou "naturalmente o processo de acumular material" como comenta Guimarães Rosa em trecho de carta dirigida ao tio Vicente (GUIMARÃES, 1972, p. 160), ele desenvolveu um trabalho de elaboração linguística a partir dessas "pesquisas". Ao anotar, seguem o meditar, o escrever e o guardar, o reescrever. A "técnica" de trabalho para o encontro da forma poética é comentada na entrevista a Lorenz:

Mas eu choco também meus livros, uma palavra, uma simples palavra, ou mesmo uma frase, pode ocupar-me durante horas ou dias [...] Nós temos de aprender de novo a dedicar muito tempo a uma ideia. Então seriam escritos de novo melhores livros. Livros nascem no pensamento; escrever é técnica e prazer no jogo com as palavras. (ROSA, 1971, p. 289)

\section{0 escritor e a busca da forma perfeita}

A leitura da correspondência de Guimarães Rosa demonstra sua constante preocupação com a expressão do conteúdo. Seu trabalho de escritura e sua "ânsia de perfectibilidade" ia além da obra pronta. Alterava tanto seus textos que o editor se viu obrigado a matrizar três deles, como ele comenta com a tradutora de sua obra para o idioma inglês:

Rever qualquer texto meu, já, de si, é qualquer coisa de tremendo, porque o meu incontentamento é crescente, a ânsia de perfectibilidade, fico querendo reformar e reconstruir tudo, é uma verdadeira tortura. Por exemplo, dir-lhe-ei que as 5 edições de "Sagarana" são todas diferentes, refeitas, remodeladas, remexidas. Por fim, para ver se eu conseguia deixar isso de lado, e me voltava para escrever outros e novos livros, o meu Editor, José Olympio, mandou matrizar ou estereotipar a composição, guardando-a nos chumbos, e impedindome, assim, de permanecer na classe de Danaíde ou Sísifo. E mandou matrizar também o "Grande Sertão: Veredas" e o "Corpo de Baile" (ROSA, 23/04/1959) 
Matrizada a composição de Grande sertão: veredas, o escritor permanece ainda na classe de Danaíde ou Sísifo. O livro "querendo ser de poesia e metafísica", mais do que outras obras, exige um árduo trabalho de acompanhamento de sua tradução, comenta Guimarães Rosa nessa mesma carta:

Como a Amiga já viu, o romance de Riobaldo é uma espécie descomedida de cetáceo, com seu toucinho todo querendo ser de poesia e metafísica. É um livro terrível, não é a-toa que o Diabo é seu personagem. Sua tradução será muitíssimo mais árdua que a de qualquer conto de "Sagarana", mais cheia de dúvidas, de peculiaridades, de ciladas e remoinhos. (ROSA, 23/04/1959)

Esse trabalho constante nas diversas fases de elaboração da obra - da pesquisa documental, da criação linguistica, ao acompanhamento de traduções - pode ser parcialmente reconstituído pela leitura de sua correspondência.

A quantidade e a diversidade do material que encontramos na correspondência de Guimarães Rosa questionários, glossários, notas, comentários sobre a obra, desenhos, indicações e referências bibliográficas - atestam a importância para os estudos da sua obra. Esse vasto material é fonte para a identificação de intertextualidades, de palavras e expressões técnicas, científicas, regionais e mitológicas, descrição de etimologias, usos e costumes, elucidação de processos de criação de neologismos, sua significação e o efeito desejado. O modo como o autor mostra suas fontes, desvenda sua língua e sua escritura na sua correspondência constitui-se em um caminho para conhecermos a gênese de sua obra e sua plataforma de escritor.

A correspondência é chave que abre e desvenda o significado e a composição de muitas de suas criações e construções insólitas, permitindo a leitura de alguns de seus neologismos, indicando as matrizes de provérbios ou frases feitas modificadas, de expressões abreviadas, explicitando a composição de metáforas, metonímias, eufemismos. Como se pode ver, a correspondência auxilia a leitura da obra. É uma leitura determinada pelo próprio autor, que pode não ser a única, visto que a construção textual, como salienta Guimarães Rosa, pode admitir outras leituras que certamente os leitores farão, pelas pistas deixadas pelo autor. Por outro lado, a partir das cartas é também possível pinçar trechos que esboçam elementos para uma poética rosiana.

\section{Referências}

BIZZARRI, Edoardo. J. Guimarães Rosa correspondência com o tradutor italiano. São Paulo: Instituto Cultural ItaloBrasileiro, 1972

DANTAS, Paulo. Sagarana emotiva. São Paulo: Duas Cidades, 1975.

GUIMARÃES, Vicente de Paula. Joãozito: infância de João Guimarães Rosa. Rio de Janeiro: José Olympio-INL, 1972.

JAKOBSON, Roman. Linguistica e poética. In: JAKOBSON, Roman. Linguistica e comunicação. São Paulo: Cultrix, 1969. p. $118-162$.

LARA, Cecília. Arquivo João Guimarães Rosa do IEB. Travessia 15, Florianópolis, v. 7. n. 15, p. 153-163, jul. 1987.

MARQUES, Osvaldino. Canto e plumagem das palavras. In: MARQUES, Osvaldino. A seta e o alvo: análise estrutural de textos e crítica literária. Rio de Janeiro: MEC/INL, 1957. p. 9-128.

NASCIMENTO, Edna Maria Fernandes dos Santos. Estudo da metalinguagem natural na obra de Guimarães Rosa. 1987. 602 fls (Doutorado em Linguística) - Universidade de São Paulo, São Paulo, 1987.

RÓNAI, Paulo. Interesse geral de uma correspondência particular. Suplemento literário d'O Estado de São Paulo. p. 6, maio 1975 .

ROSA, João Guimarães. Correspondência de João Guimarães Rosa. Fundo João Guimarães Rosa. IEB-USP.

ROSA, João Guimarães. Grande sertão: veredas. Rio de Janeiro: José Olympio, 1968.

ROSA, João Guimarães. Literatura deve ser vida: um diálogo de Günter W. Lorenz com Guimarães Rosa. In: LORENZ, G. Exposição do novo livro alemão no Brasil. Frankfurt: Am Maim, Ausstellung und Mess-Gmbh des Borsenvereins, 1971. p. 267-313.

ROSA, João Guimarães. No Urubùquaquá, no Pinhém. Rio de Janeiro: José Olympio, 1969.

ROSA, João Guimarães. Sagarana. Rio de Janeiro: José Olympio, 1965.

ROSA, João Guimarães. João Guimarães Rosa: correspondência com seu tradutor alemão Curt Meyer-Clason (1958-1967). Belo Horizonte: UMFG, 2003.

ROSA, João Guimarães. Cartas a William Agel de Mello: correspondência Guimarães Rosa. São Paulo: Ateliê, 2003.

ROSA, Vilma. Relembramentos: João Guimarães Rosa, meu pai. Rio de Janeiro: Nova Fronteira, 1983.

VERLANGIERI, Iná Valéria Rodrigues. J. Guimarães Rosa: correspondência inédita com a tradutora norte-americana Harriet de Onís. Dissertação (Mestrado em Letras) - Faculdade de Ciências e Letras da Universidade Estadual Paulista, Araraquara, 1993.

Recebido: 15 de outubro de 2013

Aprovado: 23 de janeiro de 2014

Contato: edna.fernandes@uol.com.br 